\title{
Larval distributions and the spatial patterns of settlement of an oyster reef fish: responses to flow and structure
}

\author{
Denise L. Breitburg ${ }^{1, *}$, Margaret A. Palmer ${ }^{2}$, Timothy Loher ${ }^{1}$ \\ ${ }^{1}$ The Academy of Natural Sciences, Benedict Estuarine Research Center, St. Leonard, Maryland 20685, USA \\ ${ }^{2}$ Department of Zoology, University of Maryland, College Park, Maryland 20742, USA
}

\begin{abstract}
A combination of larval behavior and physical factors influence the spatial patterns of settlement of marine organisms. Of particular importance to the settlement process is the blend of passive transport and active responses to water flow near the settlement habitat. Field experiments with the naked goby Gobiosoma bosc, a benthic oyster reef fish, indicated that larvae aggregate in low-flow areas on the downcur rent sides of rocks, and shift position with changing flow directions. Larger aggregations of larvae were found in downcurrent positions at rocks that created larger low-flow zones, and during parts of the tidal cycle with higher ambient flow velocities. Settlement occurred in a highly aggregated pattern that reflected larval distributions. Most settlement measured in a field experiment was adjacent to downcurrent sides of rocks rather than in other positions near rocks, or away from structures that would decrease downcurrent flow velocities. These results suggest that the active response of fish larvae to either direct or indirect effects of flow on reefs may be important to fine-scale spatial patterns of settlement. Because zooplankton densities downcurrent of rocks were similar to, or lower than, densities upcurrent and lateral to rocks, spatial distributions of prey are unlikely to explain larval distributions. Instead, active preference for low-flow areas may enable fish larvae to maintain their position on oyster reefs, the preferred settlement habitat.
\end{abstract}

KEY WORDS: Behavior · Chesapeake Bay · Fish larvae · Goby · Hydrodynamics · Oyster reef · Recruitment

\section{INTRODUCTION}

For marine organisms with dispersive larvae, the process of settlement determines the initial spatial milieu into which individuals enter benthic assemblages. Patterns of distribution and aggregation of individuals on spatial scales affected by larval settlement can fundamentally influence many biological interactions because these interactions often depend on density and proximity to neighbors within patches in a spatial mosaic (Malatesta 1991, Tilman 1994). For example, spatial patterns of settlement determine initial local densities, which can affect the intensity of density-dependent interactions within populations

•E-mail: breit@acnatsci.org
(Doherty 1983, Connell 1985, Hurlbut 1991, Rodriguez et al. 1993), the attraction or persistence of predators (Fairweather 1988), the level of later reproductive success (Crisp 1974, Shapiro \& Boulon 1987), and presumably, dispersal towards or away from areas with high population densities.

Hydrodynamics may play an important role in the spatial pattern of larval settlement both through active responses of larvae to flowing water, and because of passive transport. Rheotactic responses are well known for fishes, and have been demonstrated experimentally in larvae, juveniles, and adults (e.g. Arnold \& Weihs 1978, Hasler \& Scholz 1983, Champalbert \& Marchand 1994). For example, laboratory-reared sole Solea solea larvae alter their orientation in response to current velocities as low as $0.7 \mathrm{~cm} \mathrm{~s}^{-1}$ (Champalbert \& Marchand 1994). Furthermore, variation among spe- 
cies and developmental stages in their vertical distributions (Leis 1991), distance from spawning grounds (Miller 1974, Leis 1982, Leis \& Goldman 1984), and tendency to accumulate in tidal fronts and surface slicks of internal waves and Langmuir circulations (Shanks 1983, Kingsford \& Choat 1986, Kingsford et al. 1991) suggest that larval fishes respond to hydrographic features during their pelagic phase. For reef and estuarine-dependent fishes, such responses may be critical to their ability to recruit to suitable habitat for juvenile growth and later reproduction.

In contrast to the fairly large number of studies relating larval distributions and hydrographic features in the planktonic environment, the importance of hydrodynamics in the near-bottom waters overlying the reef habitat has largely been ignored in studies of the settlement and recruitment of reef fishes. The behaviors of fish larvae once they arrive at the reef habitat, and the mechanisms by which the water column overlying the reef environment influence spatial and temporal patterns of settlement, are poorly understood. This study addresses important gaps in our understanding of how flow affects 2 critical steps in the recruitment process of reef fish - the behavior and distribution of larvae just prior to settlement, and the spatial pattern of settlement. Specifically, we examine the relationships among flow, structures that modify flow, and the spatial patterns of larval aggregation and settlement of a temperate estuarine fish, the naked goby Gobiosoma bosc.

Unlike research on reef fish recruitment, studies of sessile invertebrates have implicitly considered the importance of hydrodynamics in the settlement process. These studies have demonstrated that the number, species, and spatial arrangement of invertebrate recruits can be strongly influenced by flow, and by fine-scale alterations in aspects of flow (sheer stress, turbulence, boundary layer thickness) (Butman et al. 1988a, Mullineaux \& Garland 1993, Eckman et al. 1994). Although behaviors can clearly influence invertebrate settlement (Butman et al. 1988a, Pawlik et al. 1991, Eckman et al. 1994), passive processes play an extremeiy important if not dominant role in determining settlement patterns (Butman 1987, 1989, Gross et al. 1992, Snelgrove 1994).

The differences in swimming velocity and size between fish larvae and the larvae of most invertebrates suggest that fish and invertebrate larvae differ greatly in their potential for active, rather than passive, responses to flow. Fish larvae nearing competence to settle typically have faster horizontal swimming speeds, and should, therefore, be able to swim against faster currents and withstand greater turbulence than can most invertebrate larvae. Estimates of sustained swimming speeds of fish larvae are generally on the order of 1 to 4 body lengths $s^{-1}$ (Hunter 1981, Meng 1993). For a typical $10 \mathrm{~mm}$ fish larva, this is equivalent to 1 to $4 \mathrm{~cm} \mathrm{~s}^{-1}$. In contrast, estimates of swimming velocity of noncrustacean marine invertebrate larvae are typically 1 to 2 orders of magnitude lower (Chia et al. 1984, Butman et al. 1988b, Bachelet et al. 1992). This greater swimming ability of fish larvae has the potential to increase the importance of active responses to flow in the settlement process.

The goals of this study were to determine: (1) whether naked goby larvae are predictably distributed in microhabitats with low flow rates, and (2) whether the spatial pattern of larval settlement within an oyster reef could be predicted from the relationship between flow and presettlement behavior of larvae. The naked goby is a small (maximum total length approximately $60 \mathrm{~mm}$ ) benthic fish abundant in oyster reefs and other structured habitats on the Atlantic and Gulf of Mexico coasts of North America from Massachusetts to Florida (Hildebrand \& Schroeder 1972). Postflexion (late developmental stage) 'demersal' larvae can be found singly and in schools of up to several hundred individuals within $50 \mathrm{~cm}$ of the reef substrate (Breitburg 1989, 1991). Observations of postflexion naked goby larvae in a laboratory flume indicate they can maintain their horizontal position by swimming counter to the prevailing current at velocities on the order of $\leq 3$ to $4 \mathrm{~cm}$ $\mathrm{s}^{-1}$. In the field, larvae are transported downcurrent at current velocities of 7 to $8 \mathrm{~cm} \mathrm{~s}^{-1}$ even if they are attempting to actively swim in an upcurrent direction (Breitburg unpubl. data).

The present study was prompted by the observation that naked goby larvae nearing competence to settle tend to aggregate above the oyster reef substrate near rocky outcroppings, boulders and artificial structures (Breitburg 1989, 1991). Larvae of the naked goby and a number of other reef fish species utilize the boundary layer region of the water column close to the reef substrate (e.g. Powles \& Burgess 1978, Leis 1986, Marliave 1986, Breitburg 1989, Kaufman et al. 1992). We hypothesized that the near-structure, and benthic boundary layer habitats might be selected by larvae because they are regions of reduced flow. Our results suggest that flow either directly or indirectly influences both the distribution of demersal larvae of the naked goby prior to settlement, and the fine-scale spatial pattern of settlement of these fish. In contrast to many invertebrate larvae, whose horizontal movement often results from passive transport by flow (Butman et al. 1988b), an active behavioral attraction to low-flow microhabitats by naked goby larvae appears to be an important factor determining spatial patterns in this reef fish system.

We follow the standard convention here and refer to settlement as the transition from the water column to 
the benthic habitat. For the naked goby, this transition entails a switch from swimming to benthic perching, which is rapidly followed by the acquisition of dorsal pigmentation and degeneration of the swim bladder. In order to clearly distinguish larval behaviors in the near-substrate water column from distributions of individuals that have settled, we refer to all individuals observed in the water column as larvae, and all individuals collected from the substrate as juveniles or settlers (see Breitburg 1991).

\section{METHODS}

Study site. We examined flow, larval distributions and spatial patterns of larval settlement at the Flag Pond oyster reef, located $7 \mathrm{~km}$ north of Cove Point, Maryland, USA, on the western shore of the mid Chesapeake Bay (ca $38^{\circ} 25^{\prime} \mathrm{N}, 76^{\circ} 25^{\prime} \mathrm{W}$; Fig. 1). Water depth varies from 1 to $6 \mathrm{~m}$ on the ca 81 ha reef. Oyster Crassostrea virginica shell provides fairly continuous bottom cover, interspersed with patches of sand and sediment, as well as low consolidated sandstone outcroppings and rocks (mostly $<1 \mathrm{~m}$ diameter and $<0.5 \mathrm{~m}$ high). Outcroppings and rocks, which are generally

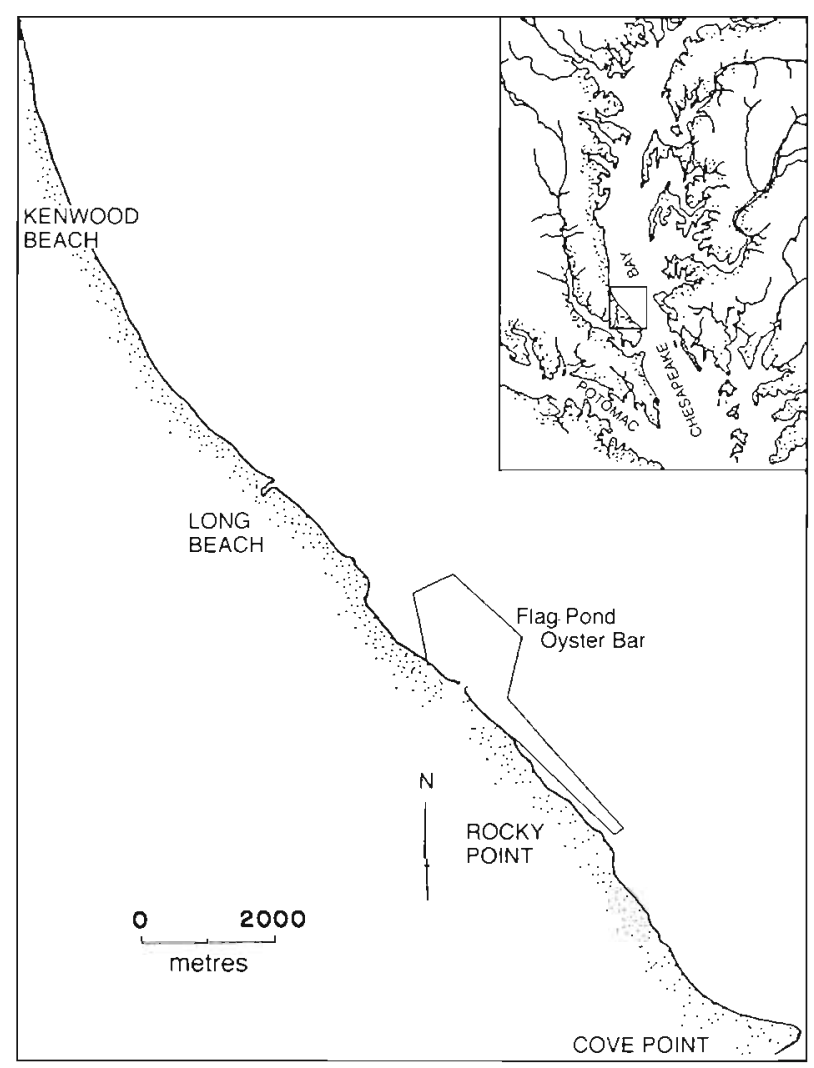

Fig. 1. Study site. The oyster reef at Flag Pond, Maryland, USA, is approximately 82 ha in area covered with oysters and other sessile invertebrates, provide high-relief structure within the oyster reefs and alter near-bottom flow. These structures become more prevalent shoreward, with continuous shell and sediment seaward. Flow at Flag Pond is predominantly bidirectional with flood tides towards the NNW (ca $334^{\circ}$; Browne \& Fisher 1988) and ebb tides towards the SSE. Salinity, temperature, and oxygen fluctuations, as well as the oyster reef fish community, are described in Breitburg (1990, 1992). The work reported here was completed near the $4 \mathrm{~m}$ site described in detail in those papers.

Flow measurements. Although flow downcurrent of structures is well known to be complex (e.g. Eckman \& Nowell 1984, Eckman 1990), mean velocity downcurrent of bluff bodies sitting on the bottom is generally reduced compared to freestream or upcurrent areas (Vogel 1981 and references therein, Abelson et al. 1993). Our goal was to collect sufficient flow data at our study site to determine if the areas downcurrent of rock outcrops were indeed characterized by reduced flow, and to estimate the linear downcurrent extent of these reduced flow zones. Thus, we measured mean velocity and direction in areas free of rock outcrops (hereafter, shelled areas) and around rocks themselves. Future studies may investigate the finer-scale relationship between flow regime and larval distribution, which would require a full characterization of the flow complexities around rocks (e.g. spatial variation in turbulence). However, such detailed measurements were beyond the scope of the present study.

To characterize general flow conditions on the reef, flow measurements were taken over shell bottom at least $2 \mathrm{~m}$ upcurrent from any rocks or outcroppings. To describe flow alterations caused by rocks or other structures, flow measurements were taken $1 \mathrm{~m}$ upcurrent of the structure (i.e. sufficiently far upstream of rocks that flow was not influenced by the rock), $5 \mathrm{~cm}$ downcurrent of the structure, at a downcurrent distance at which pathlines made by suspended particles flowing over the structure approached the substrate (indicating flow reattachment), and at an intermediate downcurrent distance approximately half way between the rock and the flow reattachment site. Flow measurements taken at least 1 to $2 \mathrm{~m}$ upcurrent of structures are referred to as ambient flows. All measurements were made with a Marsh McBirney Model 201 electromagnetic current meter fitted with a unidirectional sensor that averages current velocity over a vertical distance of $<2 \mathrm{~cm}$ and is accurate to $\pm 0.6 \mathrm{~cm}$ $\mathrm{s}^{-1}$. The word height will refer to distance above the bottom, i.e. $+z$, throughout this paper.

At each of the 4 flow measurement positions (1 upstream, 3 downcurrent), vertical velocity profiles were taken; measurements were made at $0,5,10,15$, 
30,50 and $100 \mathrm{~cm}$ heights above the substrate. Demersal naked goby larvae typically swim at heights approximately 10 to $30 \mathrm{~cm}$ above the substrate. We selected $15 \mathrm{~cm}$ as a representative height to describe current velocities that would be experienced by demersal larvae. Flows at $1 \mathrm{~m}$ above the substrate are reported to describe current speeds at a height only minimally affected by structures (all structures were 15 to $40 \mathrm{~cm}$ high in these experiments).

Structure, flow, and the spatial distribution of demersal larvae. An experiment examining numbers and sizes of schools at an array of rocks was designed to test 2 predictions that could be made if the position of larvae was dependent on reduced flow downcurrent of structures. First, larvae should be most abundant at the downcurrent sides of rocks during high flow portions of the tidal cycle. Thus at our study site during flood tides, larvae should be most abundant on the 'north' sides of rocks, and during ebb tides, larvae should be mostly on the 'south' sides of rocks. By sampling the same rocks at both flood and ebb tides, we could relate the position of larvae to flow rather than to physical features of the rocks peculiar to either northor south-facing sides. Second, larvae should be more abundant at large rocks than at small rocks because large rocks should create larger downcurrent-low flow areas than do small rocks. In addition, on 2 of the sample dates we made near slack-tide observations in order to compare larval abundances near structures under high and low flow conditions. If high abundances at large rocks were related to rock size per se rather than to the size of the low-flow zone, then larval abundances at rocks should be independent of flow velocities, and the position of larvae with respect to rocks should not shift with flow direction.

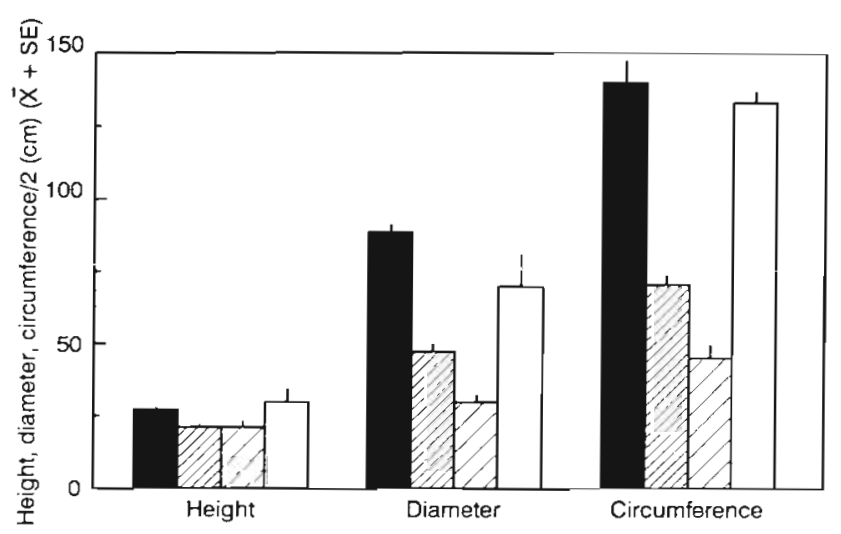

large rocks $\square$ medium rocks $\square$ small rocks $\square$ settiement rocks

Fig. 2. Gobiosoma bosc. Sizes of rocks used to determine how modification of near-bottom flow by structures influences the microhabitat distribution of naked goby larvae and the spatial pattern of settlement. Circumference of rocks was divided by 2 so that data would fit on a single vertical axis
Four replicate rocks of each of 3 size categories of were used (Fig. 2). Natural rocks collected from shallow areas of the oyster reef were arranged $2 \mathrm{~m}$ apart such that the sizes alternated along a line perpendicular to the shore and the prevailing current directions. This arrangement minimized the extent to which alterations in flow caused by rocks influenced flow 'zones' of neighboring rocks. Flow profiles were measured around rocks at a variety of free-stream velocities in order to characterize differences in flow alteration caused by the different size classes of rocks. Flow reattachment generally occurred $<1 \mathrm{~m}$ downcurrent of rocks, and lateral deflection of pathlines of suspended particles was always $\ll 1 \mathrm{~m}$, indicating that the $2 \mathrm{~m}$ spacing in the direction perpendicular to flow was adequate.

Numbers of larvae at rocks, and the position of larvae relative to rocks and flow, were estimated on 8 dates from 15 July to 26 August 1993. Exact counts of larvae could only be made for the smallest schools. Therefore, for larval aggregations containing $\geq 10$ individuals, school sizes were estimated as $10-24,25-49$, $50-99$, and $\geq 100$. On 5 dates we also measured the distance schools of larvae extended downcurrent of rocks to examine whether the linear extent of schools varied with flow velocity in the same manner as did the linear extent of downcurrent low-flow zones.

Repeated measures analysis of variance (SAS 1988) was used to test the effect of rock size, as well as sample date and the date $\times$ size interaction, on the abundance of larvae at rocks. For statistical analyses, schools sizes were scored as 0 through 5 for $0,1-9$, $10-24,25-49,50-99$, and $\geq 100$ larvae, respectively. Variances of scored school sizes for the 3 rock size treatments were not significantly different by Bartlett's test for homogeneity of variances $(\mathrm{p}>0.1)$.

Potential for passive accumulation of larvae. Organisms can accumulate in flow wakes downcurrent of structures like the large rocks used in the rock-size or settlement experiments either because of active behavioral preferences for these habitats or because they are passively suspended and retained in these locations. To distinguish behavioral preferences from passive retention we released live $(n=9)$, and dead $(n=4)$ naked goby larvae at 3 positions near one of the large rocks used for the settlement experiment described below: (1) $10 \mathrm{~cm}$ above the center of the rock, (2) $10 \mathrm{~cm}$ from the side of the rock (lateral position), $15 \mathrm{~cm}$ above the substrate, and (3) $10 \mathrm{~cm}$ downcurrent of the rock, $15 \mathrm{~cm}$ above the substrate. We use data on live larvae to determine whether larvae are capable of preventing their entrainment; we do not use these observations to examine detailed behavioral responses to flow because the behavior of live larvae likely reflected responses to handling. The dead larvae 
were killed by immersion in rose bengal stain immediately before releasing them underwater. In addition to releases of live and dead larvae, we released rhodamine dye at the same positions (above, lateral to, and downcurrent of the same rock) to track the movement of passive, neutrally buoyant particles. Larvae and dye were observed by divers, and positions were mapped with the aid of a transect line laid along the substrate and a meter stick.

Prey abundance near structures in relation to flow direction. Because larvae might aggregate in particular positions near structures if the combined effects of structure and flow influence the distribution of their prey (Alldredge \& King 1985, Palmer 1986, Walters 1986), we collected zooplankton in small-volume samples from 6 large rocks, including those used during 1993 in the rock-size experiment described above. Demersal naked goby larvae captured on oyster reefs feed primarily on pelagic copepods and invertebrate larvae (Breitburg 1991 and unpubl. data). Since naked goby larvae were most abundant downcurrent of rocks (see 'Results'), the primary comparison of interest was prey abundance downcurrent of rocks compared to that in other positions.

On each of 3 dates during the 1994 settlement season, we collected samples upcurrent of 2 rocks, at a lateral position alongside the rocks, and downcurrent of the rocks during 2 or 3 distinct portions of the tidal regime: slack tide as well as ebb flow and/or flood tide). Two different rocks were sampled on each date, for a total of 6 rocks. Samples were collected with diver-operated 'slurp guns' that quickly suctioned 21 of water. These devices were used to collect very localized samples. Each sample consisted of the contents of 2 slurp guns filled with the nozzle positioned $15 \mathrm{~cm}$ above the substrate and $20 \mathrm{~cm}$ from the rock. Immediately after samples were collected, we measured flow velocities $1 \mathrm{~m}$ upcurrent and $20 \mathrm{~cm}$ downcurrent of each rock at $0,5,10,15,30$, and $50 \mathrm{~cm}$ and $1 \mathrm{~m}$ heights above the substrate. Contents of slurp guns were emptied into containers with $35 \mu \mathrm{m}$ mesh bottoms, and preserved in ethanol with rose bengal stain.

Structure, flow, and the spatial pattern of settlement. To examine the relationships among flow, structure and the spatial pattern of settlement, we set out experimental arrays of settlement trays (Breitburg 1992) in a shell area (Fig. 3). Each array consisted of four $57 \times 67 \times 6 \mathrm{~cm}$ deep fiberglass settlement trays filled with $4 \mathrm{l}$ of sand covered by 161 of oyster shell. Settlement trays were arranged about either a central tray that contained a rock similar in size to the large rocks in the rock array experiment (Fig. 2) (structure treatment), or a flat, upsidedown tray (no-structure controls). The upsidedown central tray was the same height as the settlement trays (i.e. did not protrude

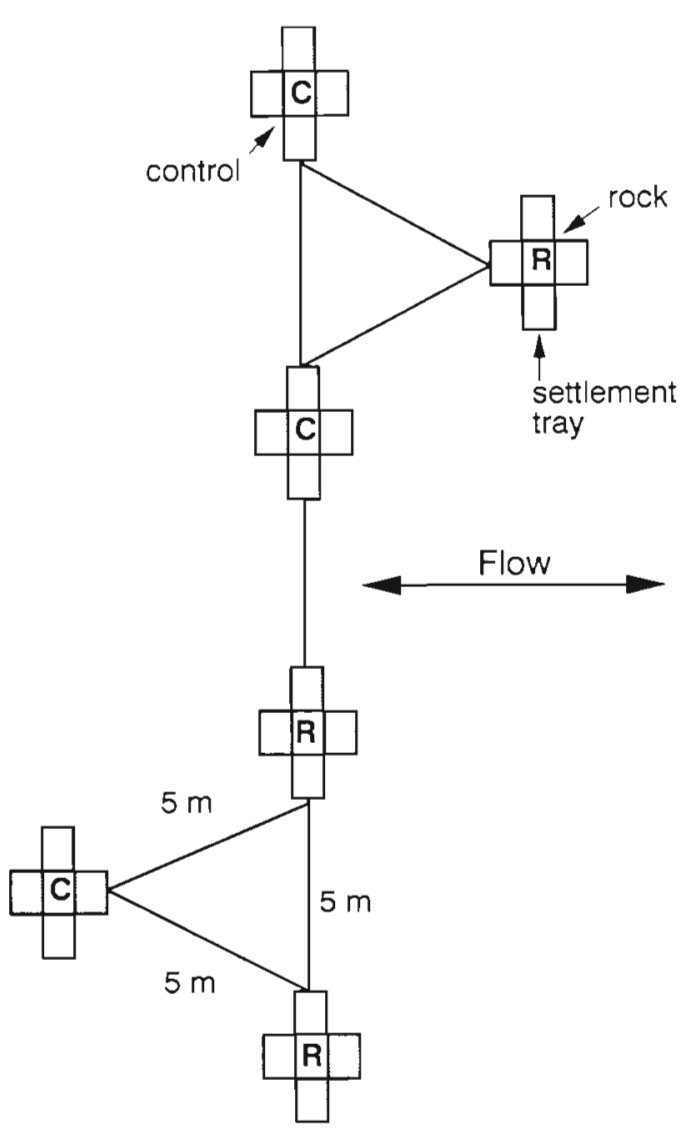

Fig. 3. Spatial arrangement of settlement trays for the field settlement experiment. Central trays either contained (R) a large rock similar in size to the large rocks in the rock array experiment, or were $(\mathrm{C}=$ controls $)$ upsidedown trays, presenting a low flat surface. Settlement trays were filled with sand and oyster shell to mimic the surrounding oyster reef substrate

further into the boundary layer), and was used to minimize flow alterations that could be caused by elevation differences between tray and substrate heights (e.g. Snelgrove 1994) in the central part of arrays. Settlement trays were positioned such that one was downcurrent of the central rock or upsidedown tray at ebb tide ('south' tray), one was downcurrent at flood tide ('north' tray), and the other two were lateral to the central rock or tray [i.e. 'east' (inshore) and 'west' (offshore) trays]. Settlement trays were contiguous with the central tray. Each structure or control array was positioned $5 \mathrm{~m}$ from the closest neighboring array. The spatial arrangement was designed to maximize the likelihood that all arrays were exposed to the same pool of larvae, which presumably could swim among arrays at slack tide, but to minimize the likelihood that larvae would be passively transported among arrays at higher flows with the potential for depletion of the larval supply by upcurrent arrays. 
Settlement trays, but not central rocks and upsidedown trays, were replaced and filled with clean sand and shell for each deployment. Trays were retrieved by divers by first covering the contents with $1 \mathrm{~mm}$ mesh netting, and then sliding trays into a nylon bag. Tray contents were sorted directly after retrieval, or were frozen for later examination. Fish were separated from sand and shell by a gravity separation method (Breitburg 1992) and were preserved in ethanol. Preserved recruits were measured, and the presence of dorsal pigmentation and an inflated swim bladder was noted.

During each of five $7-22 \mathrm{~h}$ deployments, we sampled all 3 structure treatment arrays and 3 nostructure controls. Rough seas and the time needed for handling and deploying trays prevented us from adhering to our planned 12-14 $\mathrm{h}$ deployments. Because of the short duration of the deployments, we refer to the results as settlement. Although some postsettlement movement could have occurred, the developmental stage of the settler, the lack of small, but not newly settled, juveniles in trays in this study (see 'Results') and previous experiments (Breitburg 1991) suggest such migration onto trays by small juveniles is minimal or nonexistent in short-duration experiments, and is unlikely to have influenced the patterns seen in this study.

The experiment and statistical analysis were designed to test 2 predictions: if settlement is higher where structures reduce flow during portions of the tidal cycle, then (1) settlement should be higher at rock arrays than at control arrays, and (2) within rock arrays, settlement should be higher in trays that were downcurrent of a rock during a portion of the tidal cycle (north and south trays) than in trays that were never directly downcurrent of a rock (east and west trays). We therefore considered the north and south trays (or similarly the east and west trays) at each rock or control as a single sample unit and summed their contents for statistical analyses. Data were analyzed as a repeated measures ANOVA (SAS 1988). Variation in replicate duration may have affected comparisons among replicates, but not comparisons among treatments.

Vertical velocity profiles away from structures were taken during each deployment and retrieval. In addition, dissolved oxygen, salinity and temperature were continuously monitored with a Hydrolab DataSonde III throughout the experiment to insure that settlement data were not included in analyses if oxygen concentrations during a deployment declined to levels that would induce migration or cause mortality (Breitburg 1992)
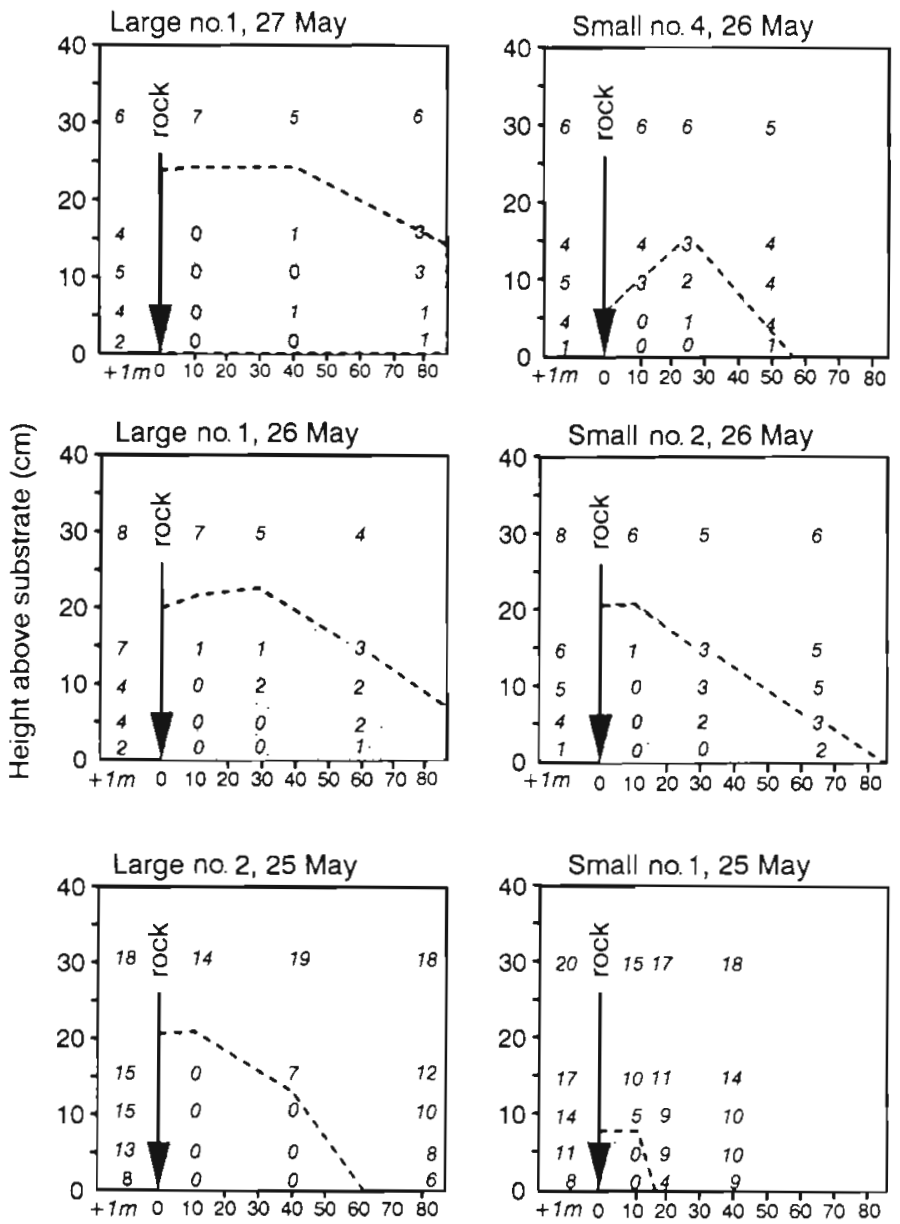

Distance downcurrent of rock $(\mathrm{cm})$

Fig. 4. Effects of structure on near-bottom flow within the Flag Pond oyster reef. Examples of vertical velocity profiles taken at large and small rocks at low-, moderate- and high-flow velocities. These examples were selected for comparison because velocity profiles $1 \mathrm{~m}$ upcurrent of the rocks were similar. Numbers within each figure are actual measured flow velocities. The shaded areas indicate the approximate extent of the downcurrent low-flow (i.e. $\leq 3 \mathrm{~cm} \mathrm{~s}^{-1}$ ) areas. These schematic drawings provide visuals of typical low-flow zones found downcurrent of all rocks. The figures are simplified representations of flow fields that are actually quite complex at finer spatial scales. Since rock heights were $\leq 25 \mathrm{~cm}$, the low-flow zones downcurrent of rocks were generally at heights $<30 \mathrm{~cm}$ off the bottom. Larvae tend to aggregate at ca 10 to $30 \mathrm{~cm}$ above the bottom. Therefore, flow reduction at $\geq 10 \mathrm{~cm}$ height is most relevant. This is especially important to note for the 25 May comparison. Although the difference between large and small rocks in the overall extent of the low-flow zone was not as striking for this date as for other comparisons shown, the degree (i.e. flow reduced to 0 to $1 \mathrm{~cm}$ $\mathrm{s}^{-1}$ ) and spatial extent of flow reduction at heights $\geq 10 \mathrm{~cm}$ were quite different. Sizes (diameter perpendicular to prevailing current direction $\times$ maximum height, $H$ ) of rocks illustrated were: large rock no. $1.90 \mathrm{~cm}$ diameter $\times 25 \mathrm{~cm} \mathrm{H}$ large rock no. 2 : $80 \mathrm{~cm}$ diameter $\times 25 \mathrm{~cm} \mathrm{H}$; small rock no. $1: 30 \mathrm{~cm}$ diameter $\times$

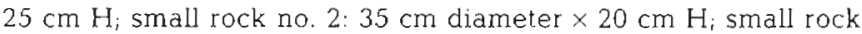
no. $4: 35 \mathrm{~cm}$ diameter $\times 15 \mathrm{~cm} \mathrm{H}$ 


\section{RESULTS}

\section{Vertical velocity profiles}

Ambient (i.e. unobstructed) flow velocities measured at $1 \mathrm{~m}$ heights $\geq 1 \mathrm{~m}$ upcurrent from structure, ranged from 0 to $31 \mathrm{~cm} \mathrm{~s}^{-1}(\mathrm{n}=86)$. Flow velocities declined sharply closer to the oyster reef bottom; at 15 and $30 \mathrm{~cm}$ heights, ambient velocities averaged approximately 60 and $67 \%$ that at $1 \mathrm{~m}$ height respectively. Flow was always substantially reduced downcurrent of rocks relative to flows $1 \mathrm{~m}$ upcurrent at any given
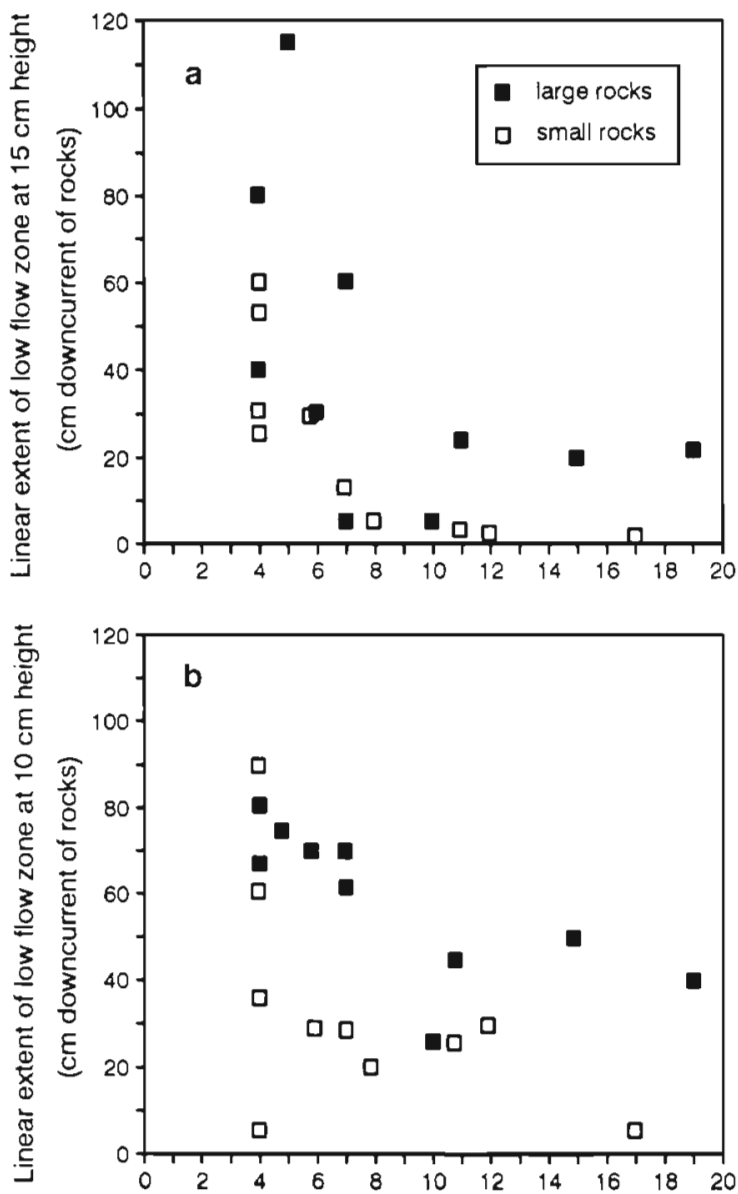

Ambient (unobstructed) flow velocity at $15 \mathrm{~cm}$ height $\left(\mathrm{cm} \mathrm{s}^{-1}\right.$ )

Fig. 5. Linear extent of downcurrent low-flow zone vs ambient $15 \mathrm{~cm}$ height flow for large and small rocks from the rock array experiment. The low-flow zone was defined as distances downcurrent of rocks with flow velocity of $\leq 3 \mathrm{~cm} \mathrm{~s}^{-1}$, a flow at which larvae can maintain their position. Larvae tend to aggregate at heights of 10 to $30 \mathrm{~cm}$ above the substrate, and thus we show the low-flow zone at heights of both $15 \mathrm{~cm}$ (top) and $10 \mathrm{~cm}$ (bottom) above the substrate. The $3 \mathrm{~cm} \mathrm{~s}^{-1}$ distance was determined by either direct measurement or by linear interpolation of data from the vertical velocity profiles. Note that the 2 extremely small low-flow zones for large rocks in Fig. 5 a were both measured at the same rock height above the bottom less than the height of the rock (Figs, $4 \& 5$ ).

Flow measurements taken at various heights $5 \mathrm{~cm}$ downcurrent of rocks, coupled with our flume observations that most larvae can maintain their position in flows up to $3-4 \mathrm{~cm} \mathrm{~s}^{-1}$, indicate that there was always a flow refuge zone for larvae downcurrent of rocks. However, the height and linear extent of the zone varied both with ambient (unobstructed) flow and rock size (Figs. 4 \& 5). In general, the downcurrent extent of the low-flow zone (defined here as areas with flow velocities $\leq 3.0 \mathrm{~cm} \mathrm{~s}^{-1}$ ) decreased with increasing ambient flow velocity. The extent of this zone decreased more rapidly for small rocks than for large rocks. At ambient flows of $\geq 8 \mathrm{~cm} \mathrm{~s}^{-1}, 15 \mathrm{~cm}$ height flows downcurrent of small rocks exceeded the swimming capabilities of larvae except for a few $\mathrm{cm}$ adjacent to each rock (Fig. 5a). The difference between the linear extent of low-flow zones near large and small rocks is even more striking at $10 \mathrm{~cm}$ height (Fig. 5b). Even at moderate flows of 5 to $8 \mathrm{~cm} \mathrm{~s}^{-1}$, flow zones $\leq 3 \mathrm{~cm} \mathrm{~s}^{-1}$ extended less than half the distance downcurrent of small rocks than of large rocks. The volume of the lowflow zone downcurrent of large rocks at any point in time should also have been much greater than that behind small rocks. The cross-flow diameter of large rocks was nearly twice that of medium-sized rocks and 3 times that of small rocks (Fig. 2). Large rocks should therefore create a much broader swath of water with low-flow velocities than that found downcurrent of medium or small rocks.

\section{Structure, flow, and the spatial distribution of demersal larvae}

We monitored larval densities within the rock array at ambient (i.e. $\geq 1 \mathrm{~m}$ upcurrent of structure) $15 \mathrm{~cm}$ height velocities of 1 to $7 \mathrm{~cm} \mathrm{~s}^{-1}$, corresponding to ambient $1 \mathrm{~m}$ height velocities of 3 to $14 \mathrm{~cm} \mathrm{~s}^{-1}$. Larvae were present at rocks on all sampling dates $(n=8)$ from 15 July to 26 August 1993 including $4 \mathrm{ebb}$ and 6 flood tide dives. However, larval abundances were too low on the first and last sample dates to permit useful comparisons among size categories of rocks (larvae were absent from most rocks and no rock had $\geq 25$ larvae during these dives). Therefore, these low-abundance samples were not included in data summaries below. The 2 low-flow (near slack-tide) samples were used only for contrast with higher flow samples from the same dates. Ambient flow velocities of $15 \mathrm{~cm}$ height for samples included in general analyses were 3 to $7 \mathrm{~cm}^{-1}$.

Larvae were found almost exclusively on downcurrent sides of rocks in the experimental rock array. During 50 of the 54 observations of larvae at rocks, rocks 


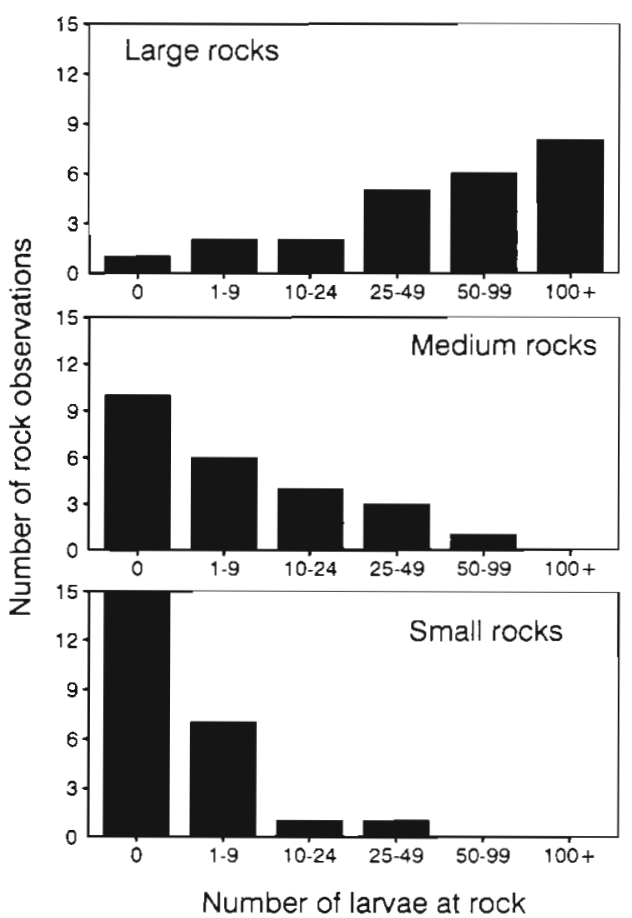

Fig. 6. Gobiosoma bosc. Larvae observed at large, medium and small rocks in the rock array experiment. Data are from the 6 dates when larvae were abundant (at least 1 rock on that date had $\geq 25$ associated larvae), and include rocks without associated larvae

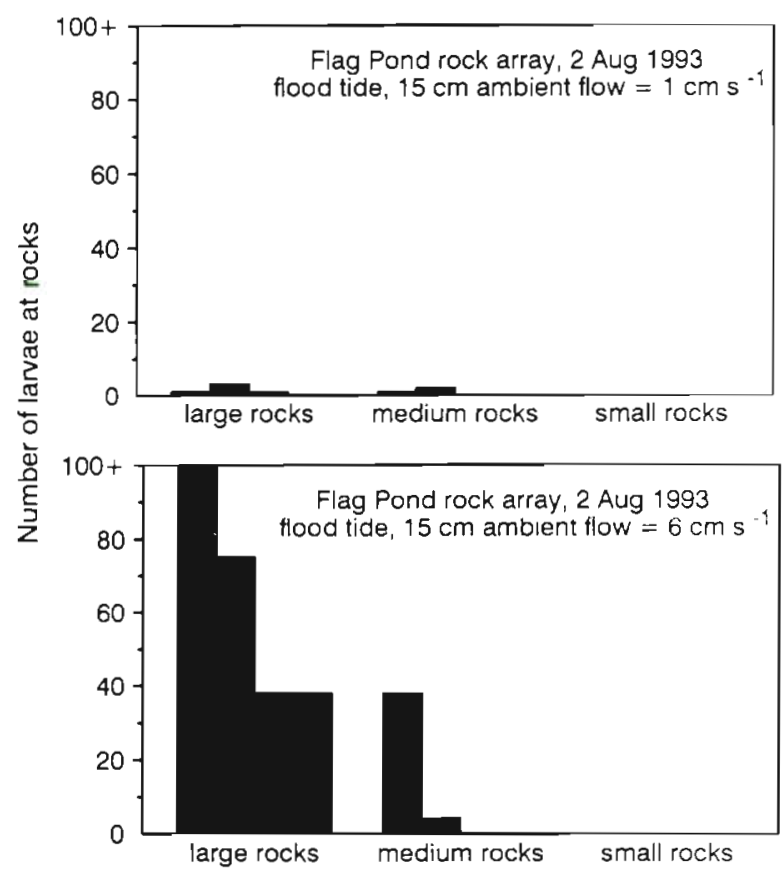

Fig. 7 Gobiosoma bosc. Larvae at the experimental rock array during 2 observations on 2 August 1993. More larvae were present during the second observation when flow velocities were higher harbored individuals, or aggregations containing 1 to $>100$ larvae, along their downcurrent edges. Of these downcurrent groups of larvae $90 \%$ were positioned within $70^{\circ}$ of the prevailing current direction (based on the 48 observations for which we had compass headings). Larvae were never observed associated with the upcurrent edges of rocks. The observations of larvae at rocks not recorded as downcurrent included a single large school centered lateral to the rock (i.e. $90^{\circ}$ from the current direction), a larva drifting with the flow, and 2 observations of individuals above the rocks.

It is important to emphasize that larvae seen downcurrent of rocks were actively swimming, not passively drifting. Their behavior at moderate and high ambient current velocities typically appeared to consist of alternating pulses of upcurrent swimming and downcurrent transport. Larvae generally oriented into the current, heads facing towards the rocks.

Near-slack and higher flow-velocity observations made only a few hours apart on 2 dates also indicate that the abundance of Iarvae at rocks may vary with ambient current velocities. On 2 August when the ambient flow at $15 \mathrm{~cm}$ height was $1 \mathrm{~cm} \mathrm{~s}^{-1}$, we found a total of only 7 larvae distributed among the rocks. Three hours later at ambient $15 \mathrm{~cm}$ flow velocities of $6 \mathrm{~cm} \mathrm{~s}^{-1}, 6$ schools of 4 to $>100$ larvae were present (Fig. 7). Similarly, during the first 9 August dive, ambient $15 \mathrm{~cm}$ flow was $4 \mathrm{~cm} \mathrm{~s}^{-1}$, and 7 groups of larvae ranging from 2 individuals to schools of 50 to 99 larvae were distributed among the 12 rocks. During the second dive $4 \mathrm{~h}$ later, we saw only 5 larvae distributed among 3 of the large rocks. During this second dive, $15 \mathrm{~cm}$ height ambient flow velocities ranged from $\ll 1 \mathrm{~cm} \mathrm{~s}^{-1}$ at the start of the survey, to $5 \mathrm{~cm} \mathrm{~s}^{-1}$ measured approximately $10 \mathrm{~min}$ after the end of the rock observations as the tide shifted from slack to flood.

More schools, and larger sizes of schools of demersal larvae, were found at large rocks than at medium or small rocks (Fig. 6j. Repeated measures ANOVA indicated significant effects of rock size and sample date, but no significant interaction term (Table 1). Of the

Table 1. Repeated measures ANOVA testing effects of sample date and rock size on the number of naked goby larvae seen at the 12 monitored rocks. For this analysis, school sizes were transformed into scores of 0 to 5 for school sizes of 0 , $1-10,11-25,26-50,51-100$, and $>100$ larvae respectively. Pillai's trace is reported for multıvariate analyses for sample date and the sample date $x$ rock size interaction (SAS 1988)

\begin{tabular}{|lrrrr|}
\hline Source & df & $\begin{array}{c}\text { Type III SS or } \\
\text { Pillai's trace }\end{array}$ & Fvalue & Pr $>F$ \\
\hline Sample date & 6 & 0.886 & 7.84 & 0.021 \\
Size & 2 & 122.694 & 19.18 & 0.001 \\
Date $\times$ Size & 10 & 0.987 & 1.17 & 0.393 \\
\cline { 1 - 3 } & & &
\end{tabular}


schools or single individuals $54 \%$ were at large rocks; all but 1 of the 16 schools with $\geq 50$ larvae were at large rocks.

The distance that large schools extended downcurrent of large rocks varied inversely with flow velocity $(\mathrm{R}=0.952, \mathrm{p}<0.05, \mathrm{n}=5)$. Of the 5 large schools at large rocks for which we have measurements, the 2 observed at $15 \mathrm{~cm}$ height ambient flows of $4 \mathrm{~cm} \mathrm{~s}^{-1}$ extended 90 and $100 \mathrm{~cm}$, the 1 school observed at $6 \mathrm{~cm}$ $\mathrm{s}^{-1}$ extended $70 \mathrm{~cm}$, and the 2 schools observed at $7 \mathrm{~cm}$ $\mathrm{s}^{-1}$ both consisted of tight groups of larvae all within $20 \mathrm{~cm}$ downcurrent of rocks. There were no significant relationships (product moment correlations all p > 0.10 ) for medium (25 to 99 larvae) or small (<25 larvae) schools with any size-class of rocks ( $\mathrm{n}=3$ to 9 for various comparisons). However, none of the 9 medium or small schools measured at $7 \mathrm{~cm} \mathrm{~s}^{-1}$ ambient flow extended more than $30 \mathrm{~cm}$ downcurrent of the rock with which they were associated.

To examine which aspect of rock size could account for the difference in numbers of larvae at large, medium and small rocks, we compared larval numbers with 2 measures of rock size per se, and with an estimate of the volume of the low-flow zone downcurrent of rocks. Note that neither of these metrics addresses the issue of why larvae associated with the downcurrent faces of rocks as these positions changed between ebb and flood tides. Cross-sectional area, estimated as the maximum height $x$ diameter of the rock in the plane perpendicular to flow, was used as a measure of the area available to larvae adjacent to rocks. Vertical downcurrent surface area, estimated as the maximum height $\times 0.5$ circumference served as a metric similar to cross-sectional area, and also as an indicator of other features of surface area - e.g. rock surface available as a source of demersal plankton and invertebrate larval prey. We estimated mean numbers of larvae at rocks using the actual numbers of larvae counted for aggregations of 0 to 9 larvae, the midpoint of school-size categories of aggregations of 10-24, 25-49 and 50-99, and 100 for aggregations of $\geq 100$. This yields an extremely conservative estimate of the mean where aggregations of $\geq 100$ larvae were common (i.e. large rocks) because school sizes sometimes reach 200 to 300 individuals.

The difference in numbers of larvae at large, medium and small rocks was much greater than the differences in rock sizes. Numbers of larvae at the 3 rock sizes (averaged across all 4 rocks in each size category and 6 observations per rock) were $61 \pm 11,11 \pm$ 6 and $3 \pm 3$ individuals for large, medium and small rocks respectively, or approximately $20: 4: 1$. In contrast, the cross-sectional areas of rocks were $2450 \pm 227$, $1013 \pm 106$ and $656 \pm 144 \mathrm{~cm}^{2}$ respectively, or $4: 2: 1$. Vertical downcurrent surface area was approximately
$3916 \pm 468,1506 \pm 67$ and $959 \pm 152 \mathrm{~cm}^{2}$ respectively, or again $4: 2: 1$.

We also compared the number of larvae at rocks to estimates of the volume of the low-flow zone downcurrent of rocks and found more similarity between larval numbers and low-flow volume. We obtained a crude estimate of the volume of low-flow water downcurrent of rocks at ambient flows exceeding the swimming speed of larvae, and within the 10 to $30 \mathrm{~cm}$ height typically used by larvae, by approximating the volume of one-fourth of an ellipsoid. The semiaxes of the ellipsoid were calculated for each rock size class as: (1) the mean rock height minus $10 \mathrm{~cm}$; (2) $0.5 \times$ mean rock cross flow diameter; and (3) mean linear extent of flow $\leq 3 \mathrm{~cm} \mathrm{~s}^{-1}$ at $10 \mathrm{~cm}$ height. For this last value, we used linear interpolations of data for the 2 to 3 sets of velocity profiles at each rock size category with ambient $15 \mathrm{~cm}$ height flows of 6 to $7 \mathrm{~cm} \mathrm{~s}^{-1}$, which corresponded to high flow velocities at which we observed large numbers of larvae at the rocks (see Fig. 5 for large and small rocks). For 2 large rocks only, $10 \mathrm{~cm}$ height flow at the farthest downcurrent measurement point was only $2 \mathrm{~cm} \mathrm{~s}^{-1}$. We took a very conservative approach (i.e. one that would likely underestimate the linear extent of low flow at large rocks) and assumed that $3 \mathrm{~cm} \mathrm{~s}^{-1}$ flow would be achieved $10 \mathrm{~cm}$ farther downcurrent than where flow was measured. Using this approach, we approximated the downcurrent lowflow volume of water to be 19980,565 and $393 \mathrm{~cm}^{3}$ for large, medium and small rocks respectively, or a ratio of $51: 1.5: 1$, when ambient flow velocities at $15 \mathrm{~cm}$ height were 6 to $7 \mathrm{~cm} \mathrm{~s}^{-1}$

\section{Potential for passive accumulation of larvae}

Approximate trajectories mapped by divers for rhodamine dye as well as live and dead larvae released near a large rock are illustrated in Fig. 8. Rhodamine dye released at ambient $15 \mathrm{~cm}$ height velocities of 6 and $11 \mathrm{~cm} \mathrm{~s}^{-1}$ indicated that passive, neutrally buoyant particles would generally be transported downcurrent past rocks on this rough shell bottom. Dye released above or beside the rock was rapidly transported downcurrent at both current velocities tested. Only dye released directly into the low-flow zone was retained in the downcurrent low-flow zone. Even then, the retention was only temporary. Within 1 to $2 \mathrm{~min}$, the dye moved in complex trajectories downcurrent of the rock.

Releases of live larvae above, lateral to, and downcurrent of a large rock clearly indicated that larvae are capable of preventing their passive entrainment downcurrent of rocks (Fig. 8). Live larvae were released individually at ambient $15 \mathrm{~cm}$ height current velocities 

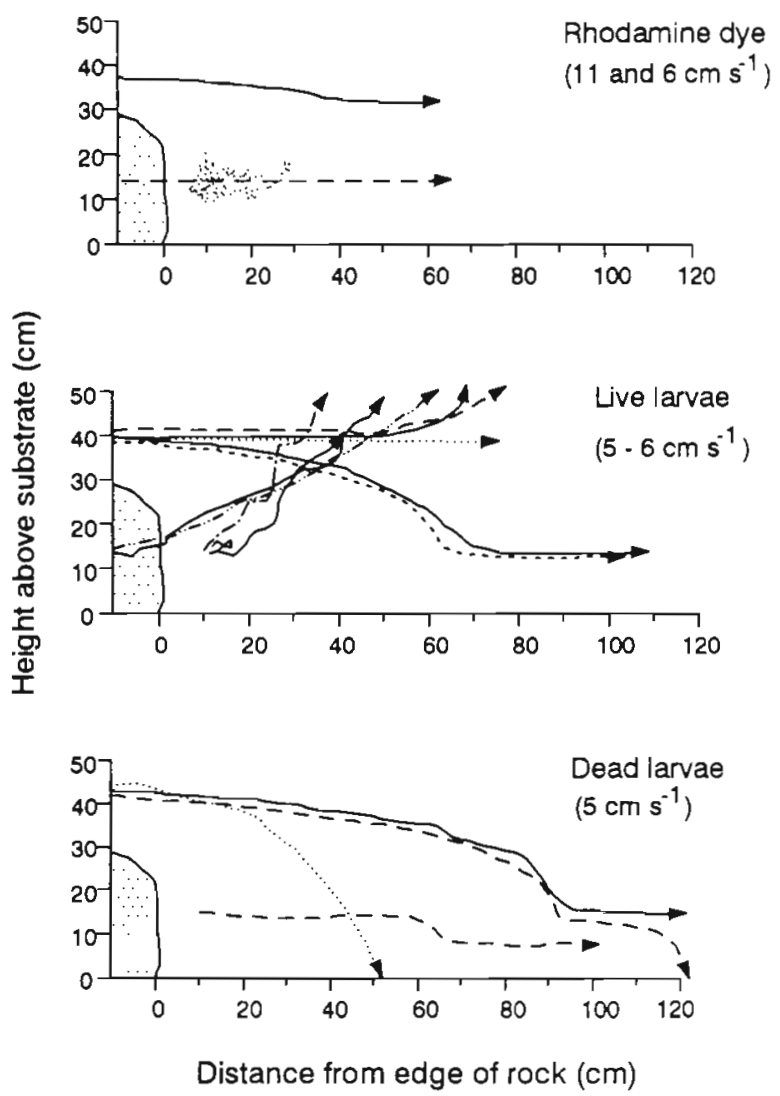

Fig. 8. Gobiosoma bosc. Approximate trajectories mapped by divers for rhodamine dye and live and dead larvae released near a large rock. Dye and larvae were released above, lateral to, and downcurrent of the rock. Each line represents a single larva released. Arrows indicate the direction larvae were swimming or being transported when divers quit tracking or lost site of larvae. Multiple releases of rhodamine dye were indistinguishable by visual observations, and are summarized in the figure. The dotted area in the rhodamine dye figure is intended to indicate temporary retention with downcurrent transport along complex trajectories for dye released directly into the low-flow zone downcurrent of the rock

of 5 to $6 \mathrm{~cm} \mathrm{~s}^{-1}$. None of the live larvae we released remained in the downcurrent low-flow zone of the rock: 8 of 9 larvae actively swam away, 1 larva appeared to have been injured and drifted downcurrent. We assume that movement away from the rock by actively swimming larvae was a response to handling.

Dead larvae either drifted downcurrent or sank to the substrate; none were retained in the low-flow zone. At $15 \mathrm{~cm}$ height ambient current velocities of 5 to $6 \mathrm{~cm} \mathrm{~s}^{-1}$, freshly dyed larvae were transported 60 to $>120 \mathrm{~cm}$ downcurrent. An interesting feature of the trajectories mapped by divers is that both the apparently injured live larva and dead larvae were typically transported downcurrent for at least brief periods at heights estimated as 10 to $20 \mathrm{~cm}$ above the substrate - heights similar to that typically observed for larvae in the field.

\section{Prey abundance near structures in relation to flow direction}

The taxonomic composition of zooplankton in 41 samples was similar for samples collected upcurrent, downcurrent and lateral to large rocks (Fig. 9). All positions were numerically dominated by calanoid copepods, primarily Acartia tonsa, which averaged $18.2 \pm 1.7(n=48)$ ind. $l^{-1}$, and $64 \pm 6 \%$ of total zooplankton in samples. Copepod nauplii comprised approximately an additional $30 \%$ of zooplankton, with harpacticoid copepods, other crustaceans, and noncrustacean zooplankton each comprising an average of less than $5 \%$ of zooplankton collected.

The spatial distribution of potential zooplankton prey of larvae differed markedly from the distribution of the fish larvae themselves. Zooplankton densities were lowest at the downcurrent position in 9 of 12 samples, and were lower than those upcurrent of rocks in 10 of 12 samples collected at $15 \mathrm{~cm}$ height flow velocities $\geq 1 \mathrm{~cm} \mathrm{~s}^{-1}$ (Fig. 10). The 2 samples with zero flow measured at $15 \mathrm{~cm}$ height were deleted from statistical analyses because flow at all sample locations (upcurrent, downcurrent and lateral) was similar at the

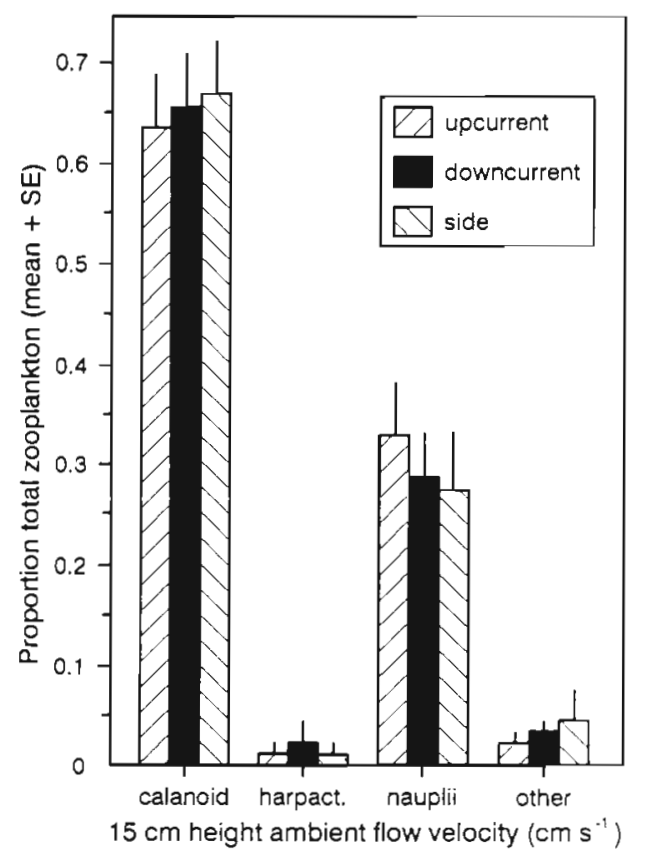

Fig. 9. Taxonomic composition of zooplankton collected in 41 samples taken near large rocks. Upcurrent, downcurrent, and lateral position samples were all numerically dominated by the calanoid copepod Acartia tonsa and copepod nauplii 


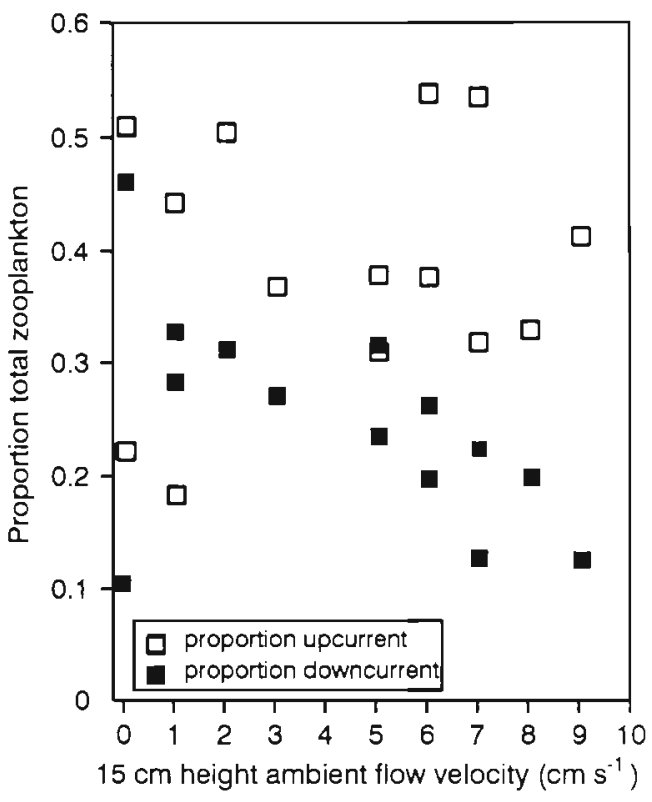

Fig. 10. Proportion of total zooplankton collected upcurrent vs downcurrent of rocks in 41 samples. Ten of twelve paired samples collected at current velocities of $>1 \mathrm{~cm} \mathrm{~s}^{-1}$ had higher zooplankton densities in upcurrent samples than in downcurrent samples

height above the substrate at which samples were collected. Preliminary ANOVA, testing the effects of the particular rock at which a sample was taken and the current velocity at $15 \mathrm{~cm}$ height on the arcsin-transformed proportion of total plankton collected in the downcurrent location, indicated that slopes were not significantly heterogeneous $(F=0.30, \mathrm{p}=0.824, \mathrm{df}=3$ for current velocity $\times$ rock interaction) and that there was no significant effect of rock identity $(F=1.03, \mathrm{p}=$ 0.488 , df $=5$ ). In subsequent analyses, samples were not blocked by rock or date. An ANOVA indicated a significant interaction effect of location (upcurrent, downcurrent or side of rock) and $15 \mathrm{~cm}$ height flow velocity on the proportion of zooplankton contained in samples (Table 2). With increasing current velocity, the difference in zooplankton densities between upcurrent and downcurrent samples increased, reflecting the

Table 2. ANOVA testing effects of location (upcurrent, downcurrent or side) and $15 \mathrm{~cm}$ height current velocity on the proportion of zooplankton collected. The location $x$ current velocity interaction SS was used as the error term to test the effect of location

\begin{tabular}{|lcccc|}
\hline Source & df & Type III SS & Fvalue & $\operatorname{Pr}>F$ \\
\hline Location & 2 & 0.0064 & 0.12 & 0.894 \\
Upcurrent velocity & 1 & 0.0002 & 0.03 & 0.862 \\
Velocity $\times$ Location & 2 & 0.0545 & 5.11 & 0.012 \\
\hline
\end{tabular}

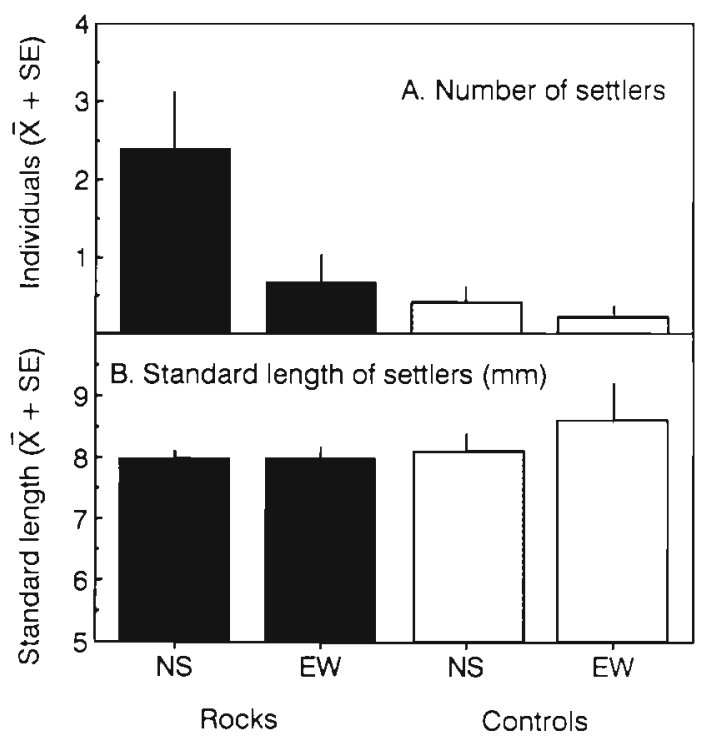

Fig. 11 Gobiosoma bosc. (A) Number and (B) sizes of naked gobies collected in settlement trays from the field settlement experiment. A total of 15 trays were deployed for each structure $x$ directions treatment. Solid bars are data from settlement trays surrounding central rocks; stippled bars are data from trays surrounding flat controls. NS: trays that were downcurrent of rocks during flood (north trays) or ebb (south trays) tides. EW: trays that were offshore (east) or inshore (west) of the central rock or control tray

decreasing proportion of zooplankton in downcurrent samples (Fig. 10; correlation: $\mathrm{r}=0.62, \mathrm{p}=0.033, \mathrm{df}=$ 12).

\section{Structure, flow, and the spatial pattern of settlement}

In the field settlement experiment, the highest settlement occurred in the same flow and structure habitats that also harbored the greatest numbers of demersal larvae - areas that were downcurrent of rocks during a portion of the tidal cycle (Fig. 11a). Of 55 settlers collected from trays, $84 \%$ were in trays in structure treatment arrays, and of these, $79 \%$ were in north or south trays, which would be downcurrent of the central rock during a portion of the tidal cycle. Repeated measures analysis of variance indicated significant (i.e. $p<0.05$ ) effects of both direction (north/south trays vs east/west trays) and structure (presence or absence of a central rock) but no significant effect of replicate and no significant interaction terms (Table 3). Divers observed schools of larvae downcurrent of rocks in structure treatment arrays during most dives, but never saw schools of larvae near the central upsidedown trays in the no-structure control arrays.

Newly settled naked gobies in trays averaged $8.0 \pm$ $0.1 \mathrm{~mm}$ standard length (SL) and ranged from 6.8 to 
Table 3. Repeated measures ANOVA testing effects of tray location (north/south vs east/west), the presence of structure (presence or absence of large central rock), and replicate on the number of naked goby larvae settling into trays during the field settlement experiment. Pillai's trace is reported for multivariate analyses for location, replicate and interaction terms

\begin{tabular}{|lrrrr|}
\hline Source & df & $\begin{array}{c}\text { Type III SS or } \\
\text { Pillai's trace }\end{array}$ & Fvalue & Pr $>F$ \\
\hline Location & 1 & 0.697 & 9.18 & 0.039 \\
Structure & 1 & 21.600 & 17.51 & 0.014 \\
Replicate & 4 & 0.997 & 85.44 & 0.081 \\
Loc $\times$ Struc & 1 & 0.553 & 4.95 & 0.090 \\
Rep $\times$ Struc & 1 & 0.889 & 2.00 & 0.482 \\
Loc $\times$ Rep & 1 & 0.979 & 11.80 & 0.215 \\
Loc $\times$ Struc $\times$ Rep & 1 & 0.990 & 21.56 & 0.160 \\
\hline
\end{tabular}

$9.9 \mathrm{~mm} \mathrm{SL}(\mathrm{n}=53)$. Mean total length (TL) was $9.6 \pm$ $0.1 \mathrm{~mm}$ (range $=80$ to $113 ; \mathrm{n}=50$ ). Settlers damaged during collection were not measured. There were no significant differences in standard length of settlers due to tray position with respect to flow (north and south trays vs east and west trays), structure treatment, or the interaction between flow and structure treatments (2-way ANOVA, all $p>0.26$; Fig 11b). All settlers retained inflated gas bladders, and had no or minimal dorsal pigmentation.

Trays were deployed for a total of 72 h during the 5 replicates, yielding mean settlement rates of 5.3 individuals $\mathrm{m}^{-2} \mathrm{~d}^{-1}$ at north and south trays in rock arrays, and 1.0 individual $\mathrm{m}^{-2} \mathrm{~d}^{-1}$ elsewhere. In addition to newly settled naked gobies, trays contained a total of 12 adult striped blennies Chasmodes bosquianus, 3 newly settled striped blennies, and 1 juvenile clingfish Gobiesox strumosus

Dissolved oxygen concentrations during the experiment remained above $1.5 \mathrm{mg}^{-1}$ during all deployments. Ambient flow velocities measured $\geq 2 \mathrm{~m}$ upcurrent of structures during settlement tray deployments ranged from 4 to $16 \mathrm{~cm} \mathrm{~s}^{-1}$ at $1 \mathrm{~m}$ height, and 1 to $8 \mathrm{~cm}$ $\mathrm{s}^{-1}$ at $15 \mathrm{~cm}$ above the substrate $(\mathrm{n}=6)$.

\section{DISCUSSION}

Results of this study suggest that larvae of the naked goby actively select the low-flow microhabitat associated with the downcurrent sides of structures, and that the location and highly aggregated spatial pattern of settlement is a direct consequence of microhabitat preferences of larvae. Demersal larvae at the Flag Pond oyster reef were strongly associated with the downcurrent sides of rocks, where flow velocities were reduced considerably below ambient levels. Aggregating in these low-flow areas would provide the clear advantage of allowing larvae nearing competence to settle to remain in habitat suitable for settlement rather than being transported off the reef to habitats less favorable for juvenile growth and survival. Newly settled naked gobies were most abundant in regions where rocks would reduce ambient flows during portions of the tidal cycle. Given the strong association of demersal larvae with downcurrent sides of rocks and the lack of larvae upcurrent of rocks, it seems reasonable to expect that those juveniles settled downcurrent, not upcurrent of structures. If this assumption is correct, then the spatial distribution of flow velocities on the oyster reef at Flag Pond influences the spatial distribution and degree of aggregation of both larval and newly settled naked gobies.

Fish larvae nearing competence to settle should have the required sensory capability to detect gradients in flow velocities, and their behavioral response to flow has been demonstrated experimentally (e.g. Champalbert \& Marchand 1994). Free neuromasts of the lateral line system enable fish to detect small variations in flow impinging on different parts of their body (Popper \& Platt 1993). Furthermore, because demersal naked goby larvae are within several $\mathrm{cm}$ of the substrate, they should also be able to visually determine whether they are maintaining their position in the face of a current, or are being transported horizontally.

The combined results of the larval releases, observations of larvae in the field, and our flow measurements at rocks strongly support the contention that the aggregated distribution of naked goby larvae downcurrent of large rocks is an active behavioral response to low current velocities in these areas, not a result of passive retention leading to accumulation of larvae. First, our releases of live larvae clearly indicate that these fish are fully capable of swimming out of the low flow zones in which they aggregate and settle in high abundances. Indeed, live wild larvae downcurrent of rocks can be seen swimming actively to maintain their position. Releases of dead larvae and dye also provide evidence against passive retention. The important point here is that larvae aggregating downcurrent of rocks are actively choosing to remain in these sites; we could clearly observe them swimming away from the exact same sites following our releases.

Second, larvae shift positions with the direction of flow. During different observations, naked goby larvae were found on both north and south sides of the same experimental rocks - whichever side was downcurrent during that particular observation. Thus, there was nothing peculiar about certain sides of the rocks per se, but rather, larvae were responding to aspects of the 'rock environment' that varied with flow conditions. Third, the 2 dates with repeated observations of the experimental rock array at high-and low-flow 
velocities, and 2 similar observations from field experiments using rock mimics (Breitburg et al. unpubl. data) indicate that larvae may be less abundant at structures when ambient current velocities do not exceed their sustained swimming speeds, than during higher flow portions of the tidal cycle. Fourth, the distance that both large schools and low-flow zones extended downcurrent of rocks were inversely related to ambient flow velocities.

Finally, the fact that larvae preferentially aggregated at large rather than small rocks in our rock-array experiment strongly supports active behavior determining distributions on the reef. These large rocks created larger downcurrent low-flow zones than did smaller rocks, especially at high ambient flow velocities. Our data do not provide information on how larvae encounter these low-flow zones. If rocks are generally intercepted as larvae are passively transported at current velocities that exceed their swimming capabilities, then aggregation downcurrent of large rocks would result primarily from a 'stay/leave' behavioral decision made upon encountering the rock or the downcurrent low-flow zone. The behavioral 'decision' to associate with a rock might also be made at low-flow velocities when larvae can control their movement among structures on the reef. Especially in this latter case, visual cues related to rock size, as well as flow velocities, could be important in the selection of 'flow refuges'.

\section{Potential consequences of spatial patterns}

The spatial patterns of larval and newly settled naked gobies may thus reflect a compromise between selection for larval behavior that increases survival of newly settled juveniles and physical constraints on larval behavior - processes that are expressed on different spatial scales. It is likely that there is selection for larval behavior that maximizes the probability that settlement occurs on oyster reefs - habitats that occur in patches of $10 \mathrm{~s}$ of meters to hectares. However, on smaller spatial scales, on the order of centimeters to meters, the flow microhabitat preferences of larvae appear to determine the spatial pattern of settlement. We suggest that newly settled juveniles were most abundant near structures and occurred in a highly aggregated pattern of dispersion because of limitations of larval swimming speeds, not because these patterns are advantageous after settlement. Even at current velocities below the swimming speeds of fish larvae, the use of low-flow microhabitats should reduce the energetic costs of maintaining a position on a reef. At this time, we have no evidence to indicate an advantage of aggregated settlement to juveniles, and obser- vations of cannibalism (Nero 1976, Breitburg et al. 1994) suggest that settlement into high density patches could increase mortality during settlement.

In addition to the direct effect of facilitating settlement onto oyster reefs, indirect effects of flow velocity could also be important to the larval stage. If larval feeding rates were higher, or predation rates on larvae were lower in low-flow velocity zones on reefs, aggregating downcurrent of structures might be an advantage during the larval stage, prior to settlement. However, our data and observations do not provide support for these contentions. Feeding rates of naked goby larvae are low on the Flag Pond reef (Breitburg 1989, 1991, \& additional unpubl. data). Furthermore, densities of the full suite of zooplankton prey of larvae were lower downcurrent of rocks than in other positions at all but the lowest current velocities. Other studies have indicated that potential prey such as demersal zooplankton and meiofauna may reach very high abundances near structures (Alldredge \& King 1985, Hicks 1986, Walters 1986), and that their entry into the water, and thus their availability as prey, may be enhanced when flow is reduced (Palmer 1986). The prey distributions we found were not necessarily surprising, however, because the abundance of passive particles and invertebrate larvae downstream of protruding bodies is influenced by a complex array of hydrodynamic and behavioral factors (Eckman 1983, 1990, Jumars \& Nowell 1984, Abelson et al. 1993, Eckman et al. 1994). Our data on prey distributions does not entirely rule out the possibility that the downcurrent sides of structures represent an advantageous feeding environment on oyster reefs for fish larvae even though prey densities were higher at high-flow positions. Larvae might be better able to simultaneously feed and maintain their position when flow velocities are well below their maximum sustained swimming speed. Many fish employ a pause/travel or saltatory search pattern for prey, in which the actual detection and initiation of a predatory response occurs only when the fish is not actively swimming (O'Brien et al. 1990). During these pauses in swimming behavior, larvae would be transported greater distances at higher flow rates. Furthermore, in flowing water, the delivery of passively transported prey may be greater if larvae maintain a fixed position relative to the substrate in areas with low-flow velocities than if they allow themselves to be passively transported at higher flow velocities in the same water parcel as their prey.

Our field observations also suggest it is unlikely that aggregating downcurrent of structures reduces mortality due to predation. Instead, the spatially predictable aggregating behavior of larvae may make these larvae more susceptible to visual predators. During 1993 at our study site, we regularly observed 
young-of-year striped bass Morone saxatilis hovering above rocks in our experimental array described here, and above experimental rock-mimics (Breitburg et al. unpubl. data). The striped bass periodically swam into the aggregations of naked goby larvae and preyed on the larvae. We also found no evidence that downcurrent sides of rocks are used as a refuge from an important nonvisual predator, the scyphomedusa Chrysaora quinquicirrha (the sea nettle) (Cowan \& Houde 1992, 1993). We saw no difference in larval distributions between dives when few or no sea nettles were seen by divers, and those dives during which it was difficult for divers to avoid being stung. In addition, laboratory experiments indicate that postflexion naked goby larvae do not behaviorally avoid sea nettle tentacles, except perhaps at spatial scales on the order of millimeters (Keister \& Breitburg unpubl. data).

\section{Is the relationship beteen flow and settlement different for fish and invertebrate larvae?}

Because of differences in swimming ability, the general relationship between flow and settlement may be quite different, although similar in importance, for most benthic invertebrates and reef fishes. The limited ability of invertebrate larvae to actively control their position against horizontal currents should lead to an increased importance of passive processes. Although preferential settlement in certain sites by invertebrate larvae has clearly been documented (e.g. Butman et al. 1988a, Pawlik et al. 1991, Grassle et al. 1992, Snelgrove et al. 1993, Eckman et al. 1994, Turner et al. 1994), advection and deposition of larvae (passive processes) have a profound impact on settlement patterns (Eckman 1983, Butman 1987, 1989, Gross et al. 1992, Snelgrove et al. 1993, Snelgrove 1994). Vertical movements in the water column can influence settlement, and may sometimes be altered in response to flow conditions (Jonsson et al. 1991, Pawlik et al. 1991, Pawlik \& Butman 1993). However, behavioral responses of invertebrate larvae are probably most important when larvae are on or very near the bottom; most cannot effectively swim horizontally to select appropriate settlement substrates, except perhaps at distances < $1 \mathrm{~mm}$ from the substrate (Butman et al. 1988b, Jonsson et al. 1991, Eckman et al. 1994; but see Pawlik \& Butman 1993). Indeed, postsettlement movements along the substrate determine the final spatial pattern of settlement in some cases (e.g Crisp 1974 , Walters 1992, Mullineaux \& Garland 1993). The spatial patterns of settlement that result from these passive processes and larval behavior have been suggested to ultimately reflect the habitat requirements of the juvenile and adult stages of benthic invertebrates (Schel- tema 1974, Chia 1978), rather than the habitat preferences of the invertebrate larvae.

In contrast to invertebrates, fish larvae have greater swimming speeds and can regulate their buoyancy by swimbladder inflation. During low-flow portions of the tidal cycle, and within low-flow areas created by structure, swimming speeds of cm-long fish larvae exceed near-bottom flow velocities and larvae can control their horizontal position. Furthermore, passive 'deposition' of fish larvae to the bottom is not an issue for the majority of reef species, which can regulate their buoyancy. Because of these features of mobility, fish larvae should be able to exert active behavioral control over selection of settlement sites over larger spatial scales than can most invertebrates. It is also important to consider that the ability of benthic fishes to alter their spatial distribution following settlement may partially shift the focus of selection for microhabitat preferences within the settlement habitat from those favoring the benthic stage towards those favoring larvae. This does not mean that there are no consequences of larval distributions to the benthic stage. Instead, the aggregating behavior of one life stage - the demersal larva may potentially increase competitive interactions, induce migration from high density patches, or attract predators important to the next stage (settled recruits) Our study suggests that it may not always be appropriate to assume that the spatial distribution or degree of aggregation of newly settled reef fishes reflects preferences of the benthic stage.

Acknowledgements. We thank the many people who assisted us with the field work described here. We especially thank $C$. Pacey, T. Manuelides, J. Pahl, W. Yates, J. Smallwood, C. Jordan, L. Kellogg, J. Hixson, Joshua Hixson, Jason Hixson, W. Keefe, A. Gerstein, T Blackledge, J. Barnes, R. Lacouture, and $B$. Albright. This work was funded by NSF grants OCE9102641 and OCE-9103877 to D.B. and M.P. and a grant to M.P. from the MD Agricultural Experiment Station.

\section{LITERATURE CITED}

Abelson A, Miloh T, Loya Y (1993) Flow patterns reduced by substrata and body morphologies of benthic organisms, and their roles in determining availability of food particles. Limnol Oceanogr 38:1116-1124

Alldredge AL, King JM (1985) The distance demersal zooplankton migrate above the benthos: implications for predation. Mar Biol 84:253-260

Arnold GP, Weihs D (1978) The hydrodynamics of rheotaxis in plaice (Pleuronectes platessa L.). J exp Biol 75:147-169

Bachelet $G$, Butman CA, Webb CM, Starczak VR, Snelgrove PVR (1992) Non-selective settlement of Mercenaria mercenaria (L.) larvae in short-term, still-water, laboratory experiments. J exp mar Biol Ecol 161:241-280

Breitburg DL (1989) Demersal schooling prior to settlement by larvae of the naked goby. Environ Biol Fish 26:97-103 
Breitburg DL (1990) Near-shore hypoxia in the Chesapeake Bay: patterns and relationships among physical factors. Estuar coast Shelf Sci 30:593-609

Breitburg DL (1991) Settlement patterns and presettlement behavior of the naked goby, Gobiosoma bosci, a temperate oyster reef fish. Mar Biol 109:213-221

Breitburg DL (1992) Episodic hypoxia in Chesapeake Bay interacting effects of recruitment, behavior, and physical disturbance. Ecol Monogr 62:525-546

Breitburg DL, Steinberg N, DuBeau S, Cooksey C, Houde ED (1994) Effects of low dissolved oxygen on predation on estuarine fish larvae. Mar Ecol Prog Ser 104:235-246

Browne DR, Fisher CW (1988) Tide and tidal currents in the Chesapeake Bay. National Oceanic and Atmospheric Administration, Office of Oceanography and Marine Assessment, Rockville, Maryland, NOAA Technical Report NOS OMA 3

Butman CA (1987) Larval settlement of soft-sediment invertebrates: the spatial scales of pattern explained by active habitat selection and the emerging role of hydrodynamical processes. Oceanogr mar Biol A Rev 25:113-165

Butman CA (1989) Sediment-trap experiments on the importance of hydrodynamical processes in distributing settling invertebrate larvae in near-bottom waters. $J$ exp mar Biol Ecol 134:37-88

Butman CA. Grassle JP, Webb CM (1988a) Substrate choices made by marine larvae settling in still water and in a flume flow. Nature 333:771-773

Butman CA, Grassle JP, Buskey EJ (1988b) Horizontal swimming and gravitational sinking of Capitella sp I. (Annelida: Polychaeta) larvae: implications for settlement. Ophelia 29:43-57

Champalbert G, Marchand J (1994) Rheotaxis in larvae and juvenile sole (Solea solea L.): influence of light conditions and sediment. J exp mar Biol Ecol 177:235-249

Chia FS (1978) Perspectives: settlement and metamorphosis of marine invertebrate larvae. In: Chia FS, Rice ME (eds) Settlement and metamorphosis of marine invertebrate larvae. Elsevier, New York, p 283-286

Chia FS, Buckland-Nicks J, Young CM (1984) Locomotion of marine invertebrate larvae: a review. Can J Zool 62: $1205-1222$

Connell JH (1985) The consequences of variation in initial settlement vs post-settlement mortality in rocky intertidal communities. J exp mar Biol Ecol 93:11-45

Cowan JH, Houde ED (1992) Size-dependent predation on marine fish larvae by ctenophores, scyphomedusae, and planktivorous fish. Fish Oceanogr 1:113-126

Cowan JH. Houde ED (1993) Relative predation potentials of scyphomedusae, ctenophores and planktivorous fish on ichthyoplankton in Chesapeake Bay. Mar Ecol Prog Ser 95:55-65

Crisp DJ (1974) Factors influencing the settlement of marine invertebrate larvae. In: Grant PT, Mackie AM (eds) Chemoreception in marine organisms. Academic Press, New York, p 177-265

Doherty PJ (1983) Tropical territorial damselfishes: is density limited by aggression or recruitment? Ecology 64:176-190

Eckman JE (1983) Hydrodynamic processes affecting benthic recruitment. Limnol Oceanogr 28:241-257

Eckman JE (1990) A model of passive settlement by planktonic larvae onto bottoms of differing roughness. Limnol Oceanogr 35:887-901

Eckman JE, Nowell ARM (1984) Boundary skin friction and sediment transport about an animal-tube mimic. Sedimentology 31:851-862

Eckman JE, Werner FE, Gross TF (1994) Modelling some effects of behavior on larval settlement in a turbulent boundary layer. Deep Sea Res II 41:185-208

Fairweather PG (1988) Consequences of supply-side ecology: manipulating the recruitment of intertidal barnacles affects the intensity of predation upon them. Biol Bull 175; $349-354$

Grassle JP, Butman CA, Mills SW (1992) Active habitat selection by Capitella sp. I larvae. II. Multiple choice experiments in still water and flume flows. J mar Res 50:717-743

Gross TF, Werner FE, Eckman JE (1992) Numerical modelling of larval settlement in turbulent bottom boundary layers. $J$ mar Res 50:611-642

Hasler AD, Scholz AT (1983) Olfactory imprinting and homing in salmon. Investigations into the mechanism of the imprinting process. Springer-Verlag, Berlin

Hicks GRF (1986) Distribution and behavior of copepods inside and outside of seagrass beds. Mar Ecol Prog Ser 31. $159-170$

Hildebrand SF, Schroeder WC (1972) Fishes of Chesapeake Bay. TFH Publications, New Jersey

Hunter JR (1981) Feeding ecology and predation of marine fish larvae. In: Lasker R (ed) Marine fish larvae: morphology, ecology and relation to fisheries. Washington Sea Grant Program, Seattle, p 33-79

Hurlbut CJ (1991) The effects of larval abundance, settlement and juvenile mortality on the depth distribution of a colonial ascidian. J exp mar Biol Ecol 150:183-202

Jonsson PR, Andre C, Lindegarth M (1991) Swimming behaviour of marne bivalve larvae in a flume boundary-layer flow: evidence for near-bottom confinement. Mar Ecol Prog Ser 79:67-76

Jumars PA, Nowell ARM (1984) Fluid and sediment dynamic effects on marine benthic community structure. Am Zool 24:45-55

Kaufman L, Ebersole J, Beets J, Mclvor CC (1992) A key phase in the recruitment of coral reef fishes: post-settlement transition. Environ Biol Fish 34:109-118

Kingsford MJ, Choat JH (1986) Influence of surface slicks on the distribution and onshore movements of small fish. Mar Biol 91:161-171

Kingsford MJ, Wolanski E, Choat JH (1991) Influence of tidally-induced fronts and langmuir circulations on the distribution and movements of presettlement fishes around a coral reef. Mar Biol 109:167-180

Leis JM (1982) Nearshore distributional gradients of larval fish (15 taxa) and planktonic crustacea (6 taxa) in Hawaii. Mar Biol 72:89-97

Leis JM (1986) Epibenthic schooling by larvae of the clupeid fish Spratelloides gracilis. Jap J Jchthyol 33:67-69

Leis JM (1991) Vertical distribution of fish larvae in the Great Barrier Reef Lagoon, Australia. Mar Biol 109:157-166

Leis JM, Goldman B (1984) A preliminary distributional study of fish larvae near a ribbon coral reef in the Great Barrier Reef. Coral Reefs 2:197-203

Malatesta RJ (1991) Growing up in crowded neighborhoods: population and spatial dynamics in a sessile marine animal. PhD dissertation, University of Connecticut, Groton

Marliave JB (1986) Lack of planktonic dispersal of rocky intertidal fish larvae. Trans Am Fish Soc 115:149-154

Meng L (1993) Sustainable swimming speeds of striped bass larvae. Trans Am Fish Soc 122:702-708

Miller JM (1974) Nearshore distribution of Hawaiian marine fish larvae: effects of water quality, turbidity and currents. In: Blaxter JHS (ed) The early life-history of fish. SpringerVerlag, New York, p 217-231

Mullineaux LS, Garland ED (1993) Larval recruitment in response to manipulated field flows. Mar Biol 116:667-683 
Nero LL (1976) The natural history of the naked goby (Gobiosoma bosci) (Perciformes: Gobiidae). MSc thesis, Old Dominion University, Norfolk

O'Brien WJ, Browman HI, Evans BI (1990) Search strategies of foraging animals. Am Sci 78:160

Palmer MA (1986) Hydrodynamics and structure: interactive effects on meiofauna dispersal. J exp mar Biol Ecol 104: $53-68$

Popper AN, Platt C (1993) Inner ear and lateral line. In: Evans $\mathrm{DH}$ (ed) The physiology of fishes. CRC Press, Boca Raton, p 99-136

Pawlik JR, Butman CA (1993) Settlement of a marine tube worm as a function of current velocity: interacting effects of hydrodynamics and behavior. Limnol Oceanogr 38: $1730-1740$

Pawlik JR, Butman CA, Starczak VR (1991) Hydrodynamic facilitation of gregarious settlement of a reef-building tube worm. Science 251:421-424

Powles H, Burgess WE (1978) Observations on benthic larvae of Pareques (Pisces: Sciaenidae) from Florida and Columbia. Copeia 1978:169-172

Rodriquez SR, Ojeda FP, Inestrosa NC (1993) Settlement of benthic marine invertebrates. Mar Ecol Prog Ser 97: $193-207$

SAS (1988) SAS/STAT user's guide. SAS Institute Inc, Cary

Scheltema RS (1974) Biological interactions determining larval settlement of marine invertebrates. Thalassia jugosl $10: 263-296$

Shanks AL (1983) Surface slicks associated with tidally forced

This article was presented by J. Pawilk, Wilmington,

North Carolina, USA internal waves may transport pelagic larvae of benthic invertebrates and fishes shoreward. Mar Ecol Prog Ser 13 $311-315$

Shapiro DY, Boulon RH (1987) Evenly dispersed social groups and intergroup competition for juveniles in a coral reef fish. Behav Ecol Sociobiol 21:343-350

Snelgrove PVR (1994) Hydrodynamic enhancement of invertebrate larval settlement in microdepositional environments: colonization tray experiments in a muddy habitat. $J$ exp mar Biol Ecol 176:149-166

Snelgrove PVR, Butman CA, Grassle JP (1993) Hydrodynamic enhancement of larval settlement in the bivalve Mulinia lateralis (Say) and the polychaete Capitella sp. I. in microdepositional environments. J exp mar Biol Ecol 168 : $71-109$

Tilman D (1994) Competition and biodiversity in spatially structured habitats. Ecology 75:2-16

Turner EJ, Zimmer-Faust RK, Palmer MA, Luckenbach M (1994) Settlement of oyster (Crassostrea virginica) larvae: effects of water flow and a water-soluble chemical cue. Limnol Oceanogr 39:1579-1593

Vogel S (1981) Life in moving fluids. Willard Grant Press Boston

Walters LJ (1992) Field settlement locations on subtidal marine hard substrata: is active larval exploration involved? Limnol Oceanogr 37:1101-1107

Walters K (1986) Diel vertical migration of sediment-associated meiofauna in subtropical sand and seagrass habitats $\mathrm{J}$ exp Biol Ecol 117:169-186

Manuscript first received: April 14, 1994

Revised version accepted: March 27, 1995 